Saudi Journal of Oral and Dental Research

Abbreviated Key Title: Saudi J Oral Dent Res

ISSN 2518-1300 (Print) |ISSN 2518-1297 (Online)

Scholars Middle East Publishers, Dubai, United Arab Emirates

Journal homepage: https://saudijournals.com/sjodr

\title{
Comparison of Frictionless Mechanic with 2 Different Bracket Design
}

\author{
RA - Rashika MDS ${ }^{1}$, PR- Priya MDS ${ }^{2}$, DV - Devaki Vijayalakshmi MDS ${ }^{3}$, BR- Balaji Rajkumar MDS ${ }^{4 *}$
}

${ }^{1}$ Former Postgraduate Student, ${ }^{3}$ Professor and Head, ${ }^{4}$ Postgraduate student, Department of Orthodontics and Dentofacial Orthopedics, Meenakshi Ammal Dental College \& Hospital, Meenakshi University (MAHER), Chennai, Tamilnadu, India

${ }^{2}$ Professor, Department of Orthodontics, Madha dental College \& Hospital, Madha Nagar, Kundrathur, Chennai - 600069

DOI: $10.36348 /$ sjodr.2020.v05i02.006 | Received: 27.01.2020 | Accepted: 03.02.2020 | Published: 23.02 .2020

*Corresponding author: Dr. Balaji Rajkumar MDS

\section{Abstract}

Aim and objectives: To measure the tip, rotation, anchorage loss and rate of retraction during the retraction of upper permanent canines with conventional Roth brackets and synergy Roth brackets using frictionless mechanics. Methodology: The samples in the present study consist of two groups between the age group of 13 to 20 years. Thirty patients who required maxillary canine retraction into first premolar extraction sites as part of their orthodontic treatment completed this study. In a random split-mouth design consisting of Group 1- Conventional Roth brackets and Group 2Synergy Roth brackets, the retraction of upper canines was performed using PG (Poul Gjessing) spring with $100 \mathrm{~g}$ of force. The amount of tip, rotation, anchorage loss and rate of retraction during canine retraction were evaluated on dental casts. Results: The rate of canine retraction was statistically and clinically significant with Synergy Roth brackets $(\mathrm{P}<$ .05), but there were no Statistical difference between Conventional Roth and Synergy Roth brackets regarding the tip, rotation and anchorage loss $(\mathrm{P}>.05)$. Conclusion: Efficient rate of canine retraction was found with Synergy Roth brackets hence it can be employed in group a anchorage cases.

Keywords: Anchorage Loss (Al), Rate Of Canien Reaction (Rcr), Synergy Roth Bracket (Srb), Conventional Roth Bracket (Crb), Poul Gjessing Spring (Pg), Tip and Rotation (Tr).

Copyright @ 2020: This is an open-access article distributed under the terms of the Creative Commons Attribution license which permits unrestricted use, distribution, and reproduction in any medium for non-commercial use (NonCommercial, or CC-BY-NC) provided the original author and source are credited.

\section{INTRODUCTION}

Orthodontic research has always been focused on the development of faster and more effective tooth movement. Most orthodontic patient's desire treatment either for crowding or anterior proclination and this may often require extraction for alignment and to correct inclination of teeth respectively. After the initial phase of orthodontic treatment i.e, levelling and aligning, the extraction space is closed either by anterior retraction or posterior protraction.

Orthodontic tooth movement during space closure can be achieved through two types of mechanics in edgewise i.e friction and frictionless mechanic.

In frictional mechanics a continuous archwire slides through the posterior brackets as the anteriors are retracted and in frictionless mechanics involves the use of closing loops made either on full or sectional arch wires [1].

The maintenance of anchorage during
orthodontic treatment requires an efficient
biomechanics. Few cases will demand high anchorage

consideration during treatment; this can be effectively achieved through various methods. One of the most efficient methods is to increase the anchorage value by increasing the anchorage unit. So, in this scenario most preferable method is to individually retract the canine using frictionless mechanic.

Use of a frictionless system accomplishes space closure by means of buccal sectional closing loops or retraction springs, making it possible to apply predetermined and precise forces which can meet the biomechanical requirements for a planned tooth movement. There are several canine retraction springs that have been developed, such as Drum retraction spring, Ricketts canine retraction spring, Burstone's Tloop canine retraction spring, Nickel titanium canine retraction spring and PG canine retraction spring, which are proved to be efficient for canine retraction.

In frictionless mechanic individual canine retraction: the first step, the canines in each quadrant is retracted to full contact with the tooth distal to the extraction space. The second step, the canines are fastened to the teeth distal to them. The ensuing 
Rashika et al; Saudi J Oral Dent Res, Feb 2020; 5(2): 120-126

grouping is then used as one anchorage unit to retract the incisors. This procedure has been called the "2-step technique [2]".

In recent years, scientific studies have further mitigated the situation by documenting that bracket design is one of the several variables capable of effecting tooth movement.3 Some of the bracket designs include damon, smart clip, speed, synergy, inovation, time 2 and quick. The SYNERGY brackets were used in this split mouth study.

Synergy bracket is a versatile, active bracket with patented rounded arch walls and floor which significantly reduces friction and binding dramatically for a gentler, more continuous force, thus reducing the total treatment duration. Additionally there is increased interbracket distance and bond strength due to its low profile and mesh bonding base.

\section{MATERIALS AND METHODS}

- The study was performed on 30 randomly selected patients, at the department of orthodontics, Meenakshi Ammal Dental College, Chennai.

- In a random, split-mouth design, Synergy Roth brackets (synergy Rmo ,Denver) and conventional Roth brackets (Gemini, 3M-Unitek) of 0.022" slot were bonded to the maxillary canines in the first and second quadrants by raffle for 30 patients who met the inclusion criteria.

- Initial alignment and levelling of the maxillary arches were performed and retraction of the canines was accomplished with PG Canine retraction spring.
- The tip, rotation, anchorloss and rate of retraction were compared using photographs and study cast analysis

\section{CASE SELECTION}

The study was performed on 30 patients, out of which 21 were females and 9 males.

\section{Inclusion criteria}

- $\quad$ Age range from 13 to 20 years.

- $\quad$ Patients with dentoalveolar Angle's Class-I Malocclusion.

- Cases with bilateral maxillary 1st pre-molar extraction.

- Moderate to maximum anchorage cases, which required individual canine retraction.

\section{Exclusion criteria}

- Patients with no history of ankylosis.

- Patients with no history of pathological conditions /syndromes.

\section{Appliance selection}

The appliance system used in the study was a 0.022-inch slot Pre-Adjusted Edgewise conventional Roth prescription brackets by $3 \mathrm{M}$ UNITEK and Synergy Roth prescription brackets by RMO.

The original PG canine retraction springs constructed from 0.016 × 0.022 inch Stainless steel straight wire (ORMCO) was used.

Landmarks used in study model analysis

The following landmarks were identified and marked on the pre-retraction and post-retraction maxillary dental casts $[9,10]$.

\begin{tabular}{|c|c|}
\hline 1. $\quad$ Anterior raphe point & The most discernable anterior point on the mid-palatal raphe \\
\hline 2. Posterior raphe point & The most discernable posterior point on the mid-palatal raphe \\
\hline 3. $\quad$ Right rugae point & The most medial point of the most distinct right rugae \\
\hline 4. $\quad$ Left rugae point & The most medial point of the most distinct left rugae \\
\hline 5. $\quad$ Right molar mesiobuccal cusp tip & The Tip of mesiobuccal cusp of the maxillary right permanent $1^{\text {st }}$ molar \\
\hline 6. Right canine cusp tip & Tip of the cusp of the maxillary right permanent canine. \\
\hline 7. $\quad$ Left molar mesiobuccal cusp tip & Tip of the mesiobuccal cusp of the maxillary left permanent $1^{\text {st }}$ molar \\
\hline 8. $\quad$ Left canine cusp tip & Tip of the cusp of the maxillary left permanent canine. \\
\hline
\end{tabular}

\section{Measurements from study casts}

RR $-\perp$ to right medial rugae point

RL $-\perp$ to left medial rugae point

CL1 $-\perp$ to pre-retraction canine tip

CL2 $-\perp$ to Post - retraction left canine tip

$\mathrm{CR} 1-\perp$ to Pre-retraction canine tip

CR2 $-\perp$ to post retraction right canine tip

ML1 $-\perp$ to pre-retraction left 1 st molar mesiobuccal cusp tip

ML2 $-\perp$ to post-retraction left 1 st molar mesiobuccal cusp tip

MR1 - $\perp$ to pre-retraction right 1 st molar mesiobuccal cusp tip
MR2 $-\perp$ to post-retraction right 1 st molar mesiobuccal cusp tip.

\section{Measuring procedures \\ Photographs of the pre-retraction and post- retraction intraoral and study casts were done (figure- $1 \mathrm{a}$ and $1 \mathrm{~b})$. Study cast with 1 to 1 duplication[12] (Figure-2) The Mid-palatal raphe was constructed by joining the anterior and posterior raphe points and used as a reference median line for measurements. The photocopies of the pre-retraction and post-retraction study casts were superimposed using the constructed mid-palatal raphe as the reference plane and the rugae}


Rashika et al; Saudi J Oral Dent Res, Feb 2020; 5(2): 120-126

points as reference points. Perpendiculars were dropped on this median line from the mesiobuccal cusp tips of the maxillary permanent 1st molars (ML1,ML2,MR1,MR2) the cusp tips of the maxillary permanent canines (CL1,CL2,CR1,CR2) and the rugae points (RR \& RL). All measurement was made twice and the mean of the two values were recorded.
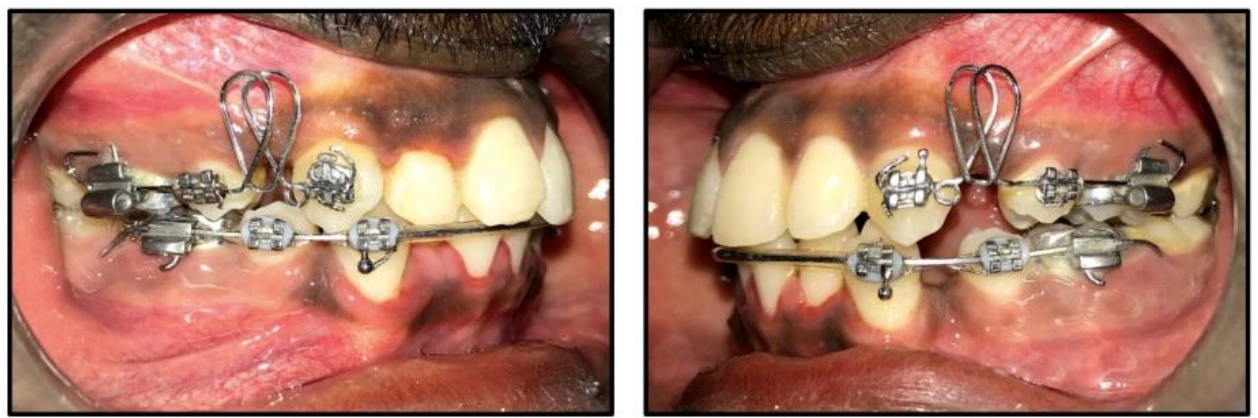

Fig-1a: Pre Retraction
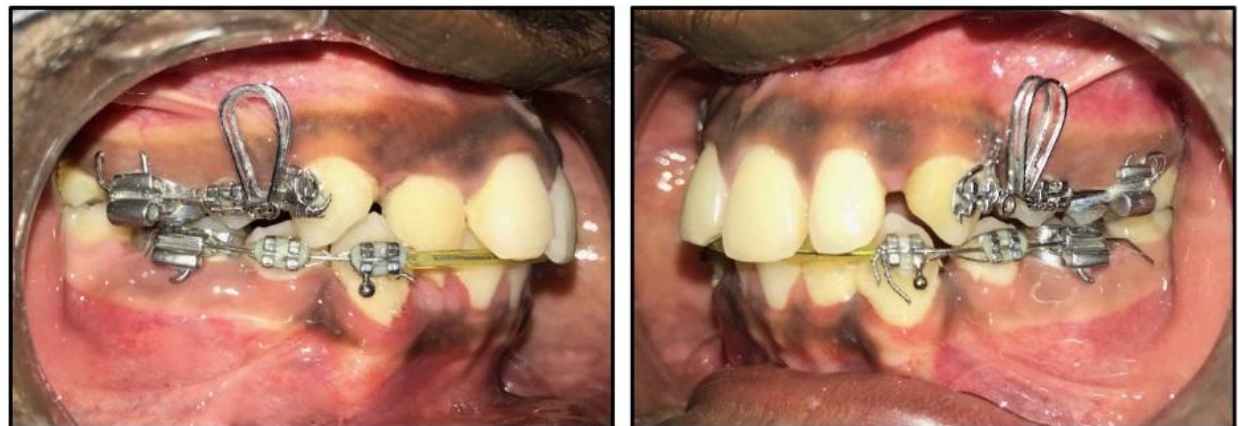

Fig-1b: Post Retraction

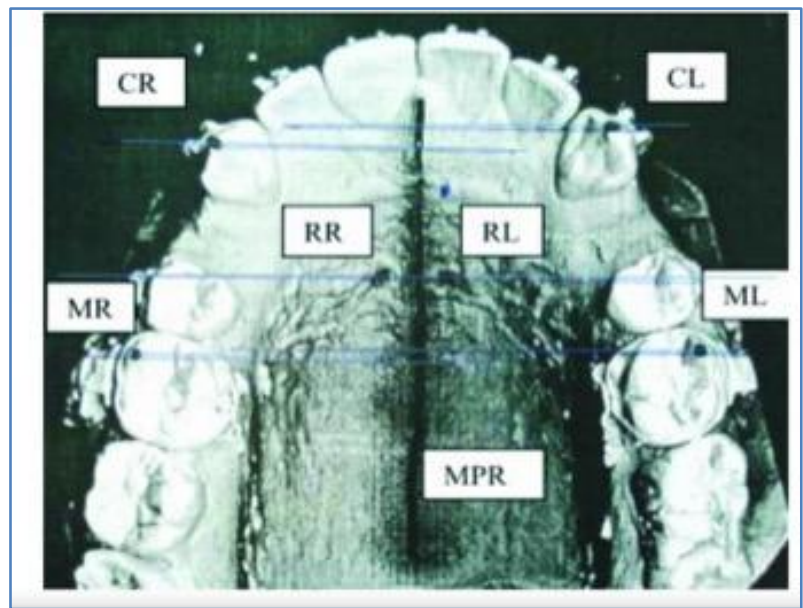

Fig-2: Study Cast with Anatomical Markings

\section{Determination of anchor loss}

The anteroposterior position of the maxillary permanent 1st molars (Anchor loss) was measured from the study cast analysis. All measurements were done using Dia calipers (MITUTOYO INC, JAPAN) (Figure-3).

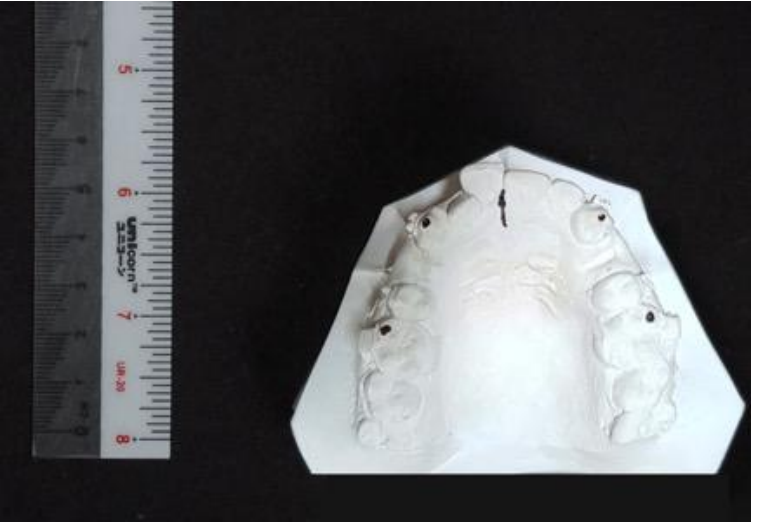

Fig-3: Measurement of Anchorage Loss

$\mathrm{ALL}=$ The distance between ML1 and ML2. $\mathrm{ALR}=\mathrm{The}$ distance between MR1 and MR2

\section{Determination of rate of canine retraction}

The linear distance from the CL1, CL2 and CR1, CR2 was measured. This distance was divided by the time interval taken for canine retraction to be completed. 


\section{Determination of canine tipping}

The measurements were carried out by using a protractor with adjustable readout arm. The facial axis of clinical crown (FACC) and its midpoint, the facial axis point, were marked on each crown of both the maxillary canines of pre and post retraction study models [14](Figure4).

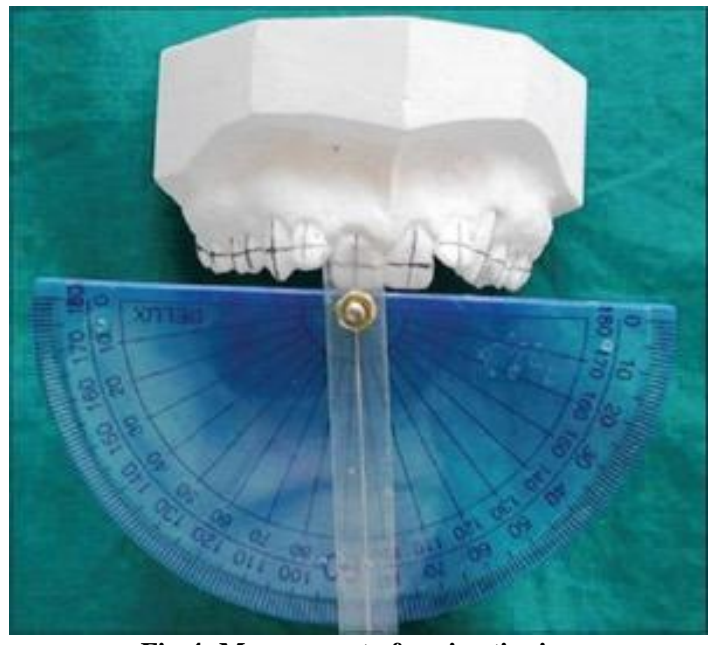

Fig-4: Measuremnt of canine tipping

\section{Measuring canine rotation}

The median raphe and the canine edges were marked with a pencil on the model and then photographed with the central projection perpendicular to the occlusal plane, along with a millimetre scale mounted on this plane .Subsequently photocopies were made, the angle between the median raphe and the line through the mesial and distal edges of the canine was measured on the photograph. In this way the rotation of the canine was recorded [13] (Figure-5).

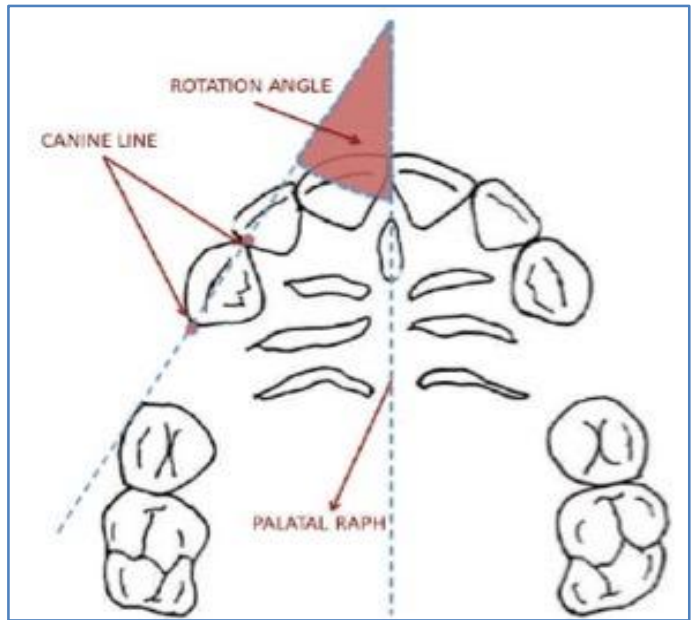

Fig-5: Measurement of rotation of canine

All the parameters were assessed from the measurements made from the study casts analysis. The result thus obtained was recorded, tabulated and statistically analyzed as follows:-

\section{STATISTICAL ANALYSIS}

Means and standard deviation were estimated from the samples for each study group.

Comparison of mean values between both the groups was estimated using paired " $t$ " test for all parameters.

In present study, $\mathrm{p}<0.05$ was considered as the level of significance and $\mathrm{p}>0.05$ was considered not significant.

\section{RESULTS}

The Independent sample ' $t$ ' tests were performed for the variables and results were tabulated.

Table-I: Amount of tipping of canines

\begin{tabular}{|c|c|c|c|c|}
\hline Variable & $\begin{array}{l}\text { Mean } \\
\text { ( in deg) }\end{array}$ & $\begin{array}{c}\text { S.D. } \\
\text { ( in deg) }\end{array}$ & $\begin{array}{c}\text { Difference Mean } \\
\text { ( in deg) }\end{array}$ & $\begin{array}{l}\mathbf{P}-\text { Value }^{\mathbf{A}} \\
\text { significance }\end{array}$ \\
\hline Conventional Roth & $3.7400^{\circ}$ & $1.05687^{\circ}$ & \multirow{2}{*}{$0.0100^{\circ}$} & \multirow{2}{*}{ Not significant } \\
\hline Synergy Roth & $3.7500^{\circ}$ & $1.05103^{\circ}$ & & \\
\hline
\end{tabular}

\section{Inference of Table I: Summary of the amount of tipping of canines:}

- In Conventional Roth for $5 \mathrm{~mm}$ of canine retraction there was a maximum tipping of $8.1^{\circ}$ and minimum of $2.8^{\circ}$ with a mean difference of $3.7400^{\circ}$.
- In synergy Roth for $5 \mathrm{~mm}$ of canine retraction there was maximum tipping of $8.1^{\circ}$ and minimum of $2.9^{\circ}$ with a mean difference of $3.7500^{\circ}$.

- The mean difference between the two groups was $0.0100^{\circ}$, which was not statistically significant. 
Table-II: Amount of Rotation of Canines

\begin{tabular}{|c|c|c|c|c|}
\hline Variable & $\begin{array}{l}\text { Mean } \\
\text { (in deg) }\end{array}$ & $\begin{array}{c}\text { S.D. } \\
\text { ( in deg) }\end{array}$ & $\begin{array}{c}\text { Difference Mean } \\
\text { ( in deg) }\end{array}$ & $\begin{array}{l}\mathbf{P}-\text { Value }^{\mathbf{A}} \\
\text { significance }\end{array}$ \\
\hline Conventional Roth & $10.1133^{\circ}$ & $0.68969^{\circ}$ & \multirow{2}{*}{$0.3134^{\circ}$} & \multirow[b]{2}{*}{ Not significant } \\
\hline Synergy Roth & $10.4267^{\circ}$ & $0.75381^{\circ}$ & & \\
\hline
\end{tabular}

Inference of Table II: Summary of the amount of rotation of canines

- In conventional Roth for $5 \mathrm{~mm}$ of canine retraction, there was a maximum rotation of $11^{\circ}$ and minimum of $9^{\circ}$, with the mean difference of $10.1133^{\circ}$.
- In synergy Roth for $5 \mathrm{~mm}$ of canine retraction, there was a maximum rotation of $11.8^{\circ}$ and minimum of $9^{\circ}$, with the mean difference of $10.4267^{\circ}$.

- The mean difference between the two groups was $0.3134^{\circ}$ which was not statistically significant.

Table-III: ANCHORAGE LOSS

\begin{tabular}{|c|c|c|c|c|}
\hline Variable & $\begin{array}{c}\text { Mean } \\
\text { (in mm) }\end{array}$ & $\begin{array}{c}\text { S.D } \\
\text { (in mm) }\end{array}$ & $\begin{array}{c}\text { Difference Mean } \\
\text { (in mm) }\end{array}$ & $\begin{array}{c}\text { p- Value }^{\mathbf{A}} \\
\text { significance }^{\text {in }}\end{array}$ \\
\cline { 1 - 3 } Conventional Roth & 0.7000 & 0.64004 & \multirow{2}{*}{0.0067} & Not significant \\
\hline Synergy Roth & 0.7067 & 0.61975 & ${ }^{A}$ Independent Sample T test \\
\hline & $* P$ value $<0.05:$ Statistically significant
\end{tabular}

Inference of Table III: Summary of anchorage loss:

- The conventional Roth bracket had a maximum anchor loss of $0.54 \mathrm{~mm}$ and minimum of $0.40 \mathrm{~mm}$ and the mean anchor loss was $0.7000 \mathrm{~mm}$.

- The synergy roth had a maximum anchor loss of $1.6 \mathrm{~mm}$ and minimum of $0.77 \mathrm{~mm}$. The mean anchor loss was $0.7067 \mathrm{~mm}$.
- The mean difference for both the brackets was $0.0067 \mathrm{~mm}$. The difference in the amount of anchor loss was not statistically significant.

Table-IV: Rate of canine retraction

\begin{tabular}{|c|c|c|c|c|}
\hline Variable & $\begin{array}{c}\text { Mean } \\
\text { (in mm/4 weeks }\end{array}$ & $\begin{array}{c}\text { S.D. } \\
\text { ( in mm / 4weeks) }\end{array}$ & $\begin{array}{c}\text { Difference Mean } \\
\text { ( in mm/ 4 weeks) }\end{array}$ & $\begin{array}{c}\text { P - Value } \\
\text { significance }\end{array}$ \\
\hline Conventional Roth & 2.1357 & 0.42968 & \multirow{2}{A}{0.1786} & Significant \\
\hline Synergy Roth & 2.3143 & 0.43682 & \\
\hline \multicolumn{4}{|c|}{${ }^{A}$ Independent Sample T test } \\
\hline
\end{tabular}

\section{Inference of Table IV: Summary of rate of canine} retraction:

- In 4-weeks' time interval, the maximum rate of retraction was $2.6 \mathrm{~mm}$ and minimum of $0.8 \mathrm{~mm}$ for conventional Roth and with the mean rate of $2.1357 \mathrm{~mm}$.

- The synergy Roth had maximum rate of $2.6 \mathrm{~mm}$ and minimum of $1 \mathrm{~mm}$ with the mean rate of $2.3143 \mathrm{~mm}$ for 4 weeks' time interval.

- The mean difference in the rates of canine retraction was $0.66 \mathrm{~mm}$ for 4 weeks' time interval, which was statistically significant.

Summarizes the comparison of all parameters with respect to Conventional Roth and the Synergy Roth, all variables were not statistically significant except for rate of retraction which was statistically significant.

\section{DISCUSSION}

Canines are of great importance for occlusion, function, stability, and esthetics. Canine retraction in edgewise mechanics can be done by either frictional or non-frictional system.

The PG canine retraction spring is one of the most efficient springs out of various springs available for canine retraction [9].

Smith and Burstone[16] suggested that 75 to 260 gms of horizontal driving forces is recommended for canine translation. Earlier studies on PG spring suggested an initial activation of 160 gms[7]. However, subsequent clinical experience showed that a reduction of the initial force level to $100 \mathrm{gms}$ did not significantly affect the rate of tooth movement. Later PG spring was designed to avoid unwanted side effects and tissue damage by keeping the force magnitude within a low range of $100 \mathrm{gms}$ in the initial activation. In the present 
study a force of $100 \mathrm{gms}$ was used similar to the study done by Poul gjessing[9]. Synergy brackets have significantly lower friction and binding than other low friction brackets as suggested by testing done using universal testing machine (Instron corp, canton, mass)[13].

Therefore this study was undertaken to compare efficacy of Synergy Roth brackets and Conventional Roth brackets during individual canine retraction using $\mathrm{PG}$ retraction spring.

Canine and molar movements were analysed on photographs of pre-retraction and post-retraction casts of the patients. Van Der Linden, Almeida et al., Ziegler and Ingervall have stated that the medial rugae points are stable reference points for analysis of mesiodistal movements of teeth. These points were used as reference points to measure anteroposterior movement of the maxillary canines and first molars. Similar to the study done by sunny jain the tipping of maxillary canines were analysed on pre and post treatment study models using protractor $[5,8,9,15]$.

\section{TIPPING OF CANINES}

The results of the present study showed a mean distal canine tipping of $3.7400^{\circ}(0.30 \% \mathrm{~mm}$ of retraction) on canines with Conventional Roth, and $3.7500^{\circ}\left(0.33^{\circ} / \mathrm{mm}\right.$ of retraction $)$ on canines with Synergy Roth. The difference in the mean value was found to be not statistically significant.

Although the tip/angulation incorporated in Conventional Roth is $13^{\circ}$ and $11^{\circ}$ in Synergy Roth, it was found that tipping occurred to same extent in both the groups [4].

Ziengler, Ingerwall and Huffman found that the mean distal tipping value was $4.5^{\circ}$ and $5.3^{\circ}$ using PG spring and pletcher spring consecutively, which was again less favourable than our study, as the standard edgewise brackets lack incorporated tip control in bracket, unlike preadjusted roth brackets[6,8].

\section{ROTATION OF CANINES}

The average distopalatal canine rotation for the canines with Conventional Roth was found to be $10.1133^{\circ}\left(2^{\circ} / \mathrm{mm}\right.$ of canine retraction), and for the canines with Synergy Roth it was $10.4267^{\circ}\left(2^{\circ} / \mathrm{mm}\right.$ of canine retraction); the difference was clinically significant and statistically not significant.

The probable reason may be because a Mesioocclusal rotation of $4^{\circ}$ is incorporated in Synergy Roth brackets, whereas Conventional Roth does not have any inbuilt rotation property, probably that's why the results were clinically significant but not statistically significant [4].
In a similar study by Ziengler. $\mathrm{P}$, Ingerwall. $\mathrm{B}$ [8], the degree of rotation was 3 times more (i.e $30^{\circ}$ ) than the present study, which was disadvantageous. And they clarify that this unfavourable outcome was due to the antirotation moment to force ratio being 4:1, which gave a lesser rotational control compared to the new version of the spring with increased antirotation moment to force ratio of $7: 1$, which was later recognized by Poul Gjessing[8]. In a study done by mezomo the the degree of rotation was similar to that of our study while comparing self-ligating and conventional brackets [13].

\section{ANCHOR LOSS}

In this study, the maxillary first molars moved mesially by an mean average value of $0.7000 \mathrm{~mm}$ and $0.7067 \mathrm{~mm}$ on Conventional Roth, and Synergy Roth respectively. The mean difference was $0.67 \mathrm{~mm}$ which was not statistically significant. It was found that anchor loss occurred to same extent in both the groups.

In this study the anchor loss was comparatively equal to the mean values found by Ziengler. P, Ingerwall.B huffman and cacciafesta using the standard edgewise brackets [6, 8]. And mezomo reported similar anchor loss values to our study [13].

\section{RATE OF RETRACTION}

The mean values for rate of canine retraction obtained in the study were $2.1357 \mathrm{~mm}$ and $2.3143 \mathrm{~mm}$ on Conventional Roth and Synergy Roth respectively for 4 weeks' time interval. The difference in the mean rates of retraction was clinically and statistically significant.

The probable reason for increased rate of canine retraction on canines with Synergy Roth may be due to Synergy's patented rounded arch walls and floor which significantly reduced friction and binding for a gentler and more continuous force [4].

The study done by Ziengler and Ingerwall using PG spring and cacciafesta et al. using ricketts spring demonstrated that the mean value of rate of tooth movement was $1.91 \mathrm{~mm}$ per month. In another study done by Huffman and way using pletcher spring the rate of canine retraction was only $1.20 \mathrm{~mm}$ per month. All these studies show a considerably much lesser value than the present study which was due to the improved design quality of the brackets in our study which reduces chair side time and patient visit intervals $[6,8,11]$.

Overall the results indicated that there was a significant difference in the rate of canine retraction, Synergy Roth brackets showed increased rate of canine retraction compared to Conventional Roth brackets. 


\section{LIMITATIONS OF THE STUDY}

Measurements were done manually using digital Vernier caliper on dental casts which can lead to manual errors. The current study had the limitation of being conducted in a smaller population.

\section{CONCLUSION}

It was concluded that Conventional Roth and Synergy Roth bracket designs had similar efficacy in relation to tip, rotation and anchor loss, whereas the rate of canine retraction was increased in Synergy Roth due to its improved bracket design qualities thus decreasing the treatment duration

\section{REFFERENCE}

1. Çetinşahin, A., Dinçer, M., Arman-Özçırpıcı, A., \& Uçkan, S. (2010). Effects of the zygoma anchorage system on canine retraction. The European Journal of Orthodontics, 32(5), 505-513.

2. Alexander, R. G. "Wick."(2008). The 20 Principles of the Alexander Discipline (1 edition). Quintessence Publishing Co Inc., U.S.

3. Frank, C. A., \& Nikolai, R. J. (1980). A comparative study of frictional resistances between orthodontic bracket and arch wire. American Journal of Orthodontics, 78(6), 593-609.

4. Robert, T., Rudman. (2007). Synergy R bracket, Semantic scholar; clinical review, 2007-2008.

5. Van der Linden, F. P. (1978). Changes in the position of posterior teeth in relation to ruga points. American journal of orthodontics, 74(2), 142-161.

6. Huffman, D. J., \& Way, D. C. (1983). A clinical evaluation of tooth movement along arch wires of two different sizes. American journal of orthodontics, 83(6), 453-459.

7. Gjessing, P. (1985). Biomechanical design and clinical evaluation of a new canine-retraction spring. American Journal of orthodontics, 87(5), 353-362.
8. Ziegler, P., \& Ingervall, B. (1989). A clinical study of maxillary canine retraction with a retraction spring and with sliding mechanics. American Journal of Orthodontics and Dentofacial Orthopedics, 95(2), 99-106.

9. Poul gjessing. (1994). PG canine retraction spring. Journal of Clinical Orthodontics; 23(5):97-113.

10. Almeida, M. A., Phillips, C., Kula, K., \& Tulloch, C. (1995). Stability of the palatal rugae as landmarks for analysis of dental casts. The Angle Orthodontist, 65(1), 43-48.

11. Pilon, J. J., Kuijpers-Jagtman, A. M., \& Maltha, J. C. (1996). Magnitude of orthodontic forces and rate of bodily tooth movement. An experimental study. American Journal of Orthodontics and Dentofacial Orthopedics, 110(1), 16-23.

12. M'Lissa, M. R., \& Sadowsky, C. (1997). Efficacy of intraarch mechanics using differential moments for achieving anchorage control in extraction cases. American journal of orthodontics and dentofacial orthopedics, 112(4), 441-448.

13. Mezomo, M., de Lima, E. S., de Menezes, L. M., Weissheimer, A., \& Allgayer, S. (2011). Maxillary canine retraction with self-ligating and conventional brackets: A randomized clinical trial. The Angle Orthodontist, 81(2), 292-297.

14. Megat Abdul Wahab, R., Idris, H., Yacob, H., \& Zainal Ariffin, S. H. (2012). Comparison of selfand conventional-ligating brackets in the alignment stage. The European Journal of Orthodontics, 34(2), 176-181.

15. Jain, S., Kiran, H. J., Neha, K., Bhattacharjee, D., Rana, S., \& Nayyar, A. S. (2017). Assessment of tip, torque, and tooth size discrepancies in Angle's class II division 2 malocclusion. International Journal of Orofacial Biology, 1(1), 4.

16. Burstone, C. J., \& Pryputniewicz, R. J. (1980). Holographic determination of centers of rotation produced by orthodontic forces. American journal of orthodontics, 77(4), 396-409. 